\title{
Efficacy of Combined Trichloroacetic Acid Peel and Topical Ascorbic Acid in Treating Epidermal Melasma
}

\section{Sidra Syeda', Arif Jamal', Muhammad Saleh Faisal ${ }^{3}$, Muhammad Sohaib $^{4}$}

'Department of Dermatology, Pak-Emirates Military Hospital, Rawalpindi, ${ }^{2}$ Health Department, Khyber Pakhtunkhwa, ${ }^{3}$ Department of Pharmacology, Khyber Medical College, Peshawar, ${ }^{4}$ Institute of Cancer Therapeutics, University of Bradford, England.

\begin{abstract}
Background: Melasma, a common dermatological problem which has no standard recommended therapy. This study aimed to compare the clinical efficacy of combined trichloroacetic acid peel and ascorbic acid with trichloroacetic acid peel alone in epidermal melasma.

Methods: A quasi-experimental study was conducted on 148 patients with epidermal melas$\mathrm{ma}$, in the dermatology department of Pak Emirates Military Hospital, Rawalpindi from August 2019 to January 2020. Patients were randomly allocated into two groups; Group A ( $n=74)$ was given trichloroacetic acid peel $20 \%$ (weekly) plus ascorbic acid cream (once daily). Group B $(n=74)$ was given trichloroacetic acid peel alone (weekly). Melasma Area and Severity Index (MASI) scores were calculated at baseline visit, $6^{\text {th }}$ week and $3^{\text {rd }}$ month. Efficacy was measured as a reduction in post-treatment MASI score to $\leq 10$. Post-stratification Chi-square test was applied considering $p$-value $\leq 0.05$ as statistically significant.
\end{abstract}

Results: The mean age of patients was $31.63 \pm 8.20$ years with a predominance of female gender $117(79.1 \%)$. The mean duration of persistence of melasma symptoms was $42.59 \pm 21.56$ months while Fitzpatrick type IV (51\%) was revealed as the dominant skin type. MASI score at the baseline, $6^{\text {th }}$ week and $3^{\text {rd }}$ month visits were $18.11 \pm 3.49,12.48 \pm 3.16$ and $7.74 \pm 3.91$, respectively. Overall, the treatment was efficacious in $106(71.6 \%)$ patients. Reduction in MASI score was significantly higher in group A (83.8\%) than group B (59.5\%).

Conclusion: The combination of trichloroacetic acid peel and ascorbic acid was more effective than trichloroacetic acid peel alone $(p=0.001)$ in the treatment of epidermal melasma.

Keywords: Ascorbic Acid; Trichloroacetic Acid; Melasma; Efficacy.

\section{Corresponding Author:}

\section{Dr. Muhammad Saleh Faisal}

Department of Pharmacology,

Khyber Medical College,

Peshawar, Pakatan.

Email: drsalehfaisal@gmail.com

https://doi.org/10.36283/PJMD11-1/010

How to cite: Syeda S, Jamal A, Faisal MS, Sohaib M. Efficacy of Combined Trichloroacetic Acid Peel and Topical Ascorbic Acid in Treating Epidermal Melasma. 2022;11(1): 56-62. doi: 10.36283/PJMD11-1/010

\section{INTRODUCTION}

Melasma is an acquired circumscribed, brown, or sometimes greyish brown hyperpigmentation of the skin that appears exclusively in sun-exposed areas, mostly on the face. It is more common in women accounting up to $90 \%$ of cases, though cases in 
men have also been reported'. It is a common disorder affecting millions of people worldwide, with exact prevalence varying between $1.5 \%$ to $33.3 \%$ depending on the population ${ }^{2}$. The condition is more common in higher skin types (Fitzpatrick skin types III, IV and V) especially in people of East Asian, South-East Asian, and Hispanic origin with intense ultraviolet exposure.

The exact pathogenesis of melasma remains unknown but factors postulated in the pathogenesis include genetic predisposition, exposure to sunlight, oral estrogen-progesterone therapies, pregnancy, thyroid dysfunctions, cosmetics and certain drugs like anti-epileptic agents ${ }^{3}$. The Wood's lamp examination classified melasma into three types i.e. epidermal melasma, dermal melasma and mixed type ${ }^{4}$.

Melasma is common but difficult to treat medical due to its recurrence. The currently available therapeutic options include hypo-pigmenting agents, broad-spectrum sunscreens, chemical peels and different physical modalities like cryosurgery and laser therapy ${ }^{5}$. Various topical agents have been used but no single agent has been proven to be effective in the management of melasma for all patients ${ }^{6-10}$. Chemical peeling is considerably safe and used in a variety of dermatological conditions besides melasma ${ }^{6}$. It is divided into superficial, medium and deep chemical peels depending on the therapeutic intent and the kind of peeling agent used"1. It causes chemical burn-induced exfoliation of the superficial layers of skin?

Trichloroacetic acid (TCA) peel is used as both superficial depth (10-25\% concentration) and deeper depth (35\% concentration) peel. It has been well studied and found versatile in its ability to clear melasma ${ }^{7,9}$. Its effectiveness can be increased by combining with other suitable therapeutic agents. TCA peel alone has a reported efficacy of $66 \%$ whereas the combination of TCA peel and topical magnesium ascorbyl phosphate has an efficacy of $81 \%^{5,11}$. As $5 \%$ ascorbic acid is comparable in efficacy to $4 \%$ hydroquinone but with lesser side effects, so ascorbic acid is a novel alternative ${ }^{12}$. It suppresses melanin synthesis by its anti-oxidant effect or by inhibiting tyrosinase ${ }^{13}$.

The objective of this study was to evaluate the efficacy of combined TCA peel plus topical ascorbic acid versus TCA peel alone because to the best of our knowledge such comparative study has never been conducted in our local population. The results can be shared with regional dermatologists along with a recommendation to adopt this drug combination in patients with epidermal melasma.

\section{METHODS}

A quasi-experimental study was conducted in the dermatology department of Pak Emirates Military Hospital, Rawalpindi from August 2019 to January 2020 after taking approval from the ethical and research committee. One hundred and forty-eight patients of both genders and age groups between 18-60 years were selected from the outpatient setting through a non-probability convenient sampling technique using a $5 \%$ level of significance, $90 \%$ power of a test. The $87 \%$ proportion of effectiveness of Trichloroacetic acid peel plus ascorbic acid cream and $67 \%$ proportion of effectiveness of Trichloroacetic acid peel alone in the treatment of melasma ${ }^{14}$. Patients with Fitzpatrick skin type III, IV , or $\checkmark$ suffering from epidermal melasma for more than 3 months and having MASI (Melasma Area and Severity Index) score $\geq 12$ was enrolled in the study. Whereas, patients with dermal or mixed melasma, Fitzpatrick skin type I, II or VI, those with keloids, history of hypertrophic scars, recurrent herpes simplex infections, or who received treatment for melasma in the last 3 months were excluded from the study to avoid biasness.

After taking informed consent from participants, detailed history and clinical examination were carried out. The eligible patients were randomly allocated into two groups (74 each). Patients in group A were subjected to combination therapy i.e., Trichloroacetic acid peel 20\% (weekly) plus Ascorbic acid cream (once daily) while patients in group B were subjected to Trichloroacetic acid peel $20 \%$ alone (weekly). Peeling was done weekly for 6 weeks and MASI scoring was done at the initial baseline visit, $6^{\text {th }}$ week and $3^{\text {rd }}$ month of the treatment. It is a reliable and systematic scoring of melasma severity that takes into account the measurement of the area involved by allocating pre-determined percentages to various areas of the face, darkness of the involved area by an arbitrary grading in comparison to the surrounding normal skin ${ }^{15,16}$. The range of the total score is 0 to 24 . Efficacy of the study drugs was measured as reduction in post-treatment MASI score to 10 or below. All the observations, MASI scoring and peeling procedures were conducted under the supervision of an expert dermatologist.

After recording data in a pre-designed proforma, its analysis was done using SPSS version 20. Mean \pm SD was calculated for numerical variables like age, duration of melasma and MASI scores. Frequencies and percentages were calculated for categorical variables like gender, efficacy, and skin types. Efficacy in both treatment groups was stratified among gender, age, skin types, baseline MASI score and duration of symptoms to see the effect modification. Post-stratification Chi-square test was also applied considering $p \leq 0.05$ as statistically significant. 


\section{RESULTS}

In this experimental study, 148 patients of epidermal melasma were enrolled having a mean age of $31.63 \pm 8.20$ years and predominance of female gender i.e., 117 (79.1\%). The mean duration of melasma symptoms was $42.59 \pm 21.56$ months. Most of the patients i.e., 81 (54.7\%) were in the age group
$>30$ years whereas 67 (45.3\%) patients were of age $<30$ years. The Fitzpatrick skin type analysis revealed type IV as the most dominant skin type (51\%) followed by type III (35\%) and type V (14\%). The mean MASI score at the baseline visit, $6^{\text {th }}$ week and $3^{\text {rd }}$ month were $18.11 \pm 3.49,12.48 \pm 3.16$ and $7.74 \pm 3.91$, respectively.

Table 1: Comparison of variables between treatment groups.

\begin{tabular}{|l|c|c|c|}
\hline Parameter & $\begin{array}{c}\text { Group A } \\
\text { (Trichloroacetic acid peel } \\
\text { + Ascorbic acid) }\end{array}$ & $\begin{array}{c}\text { Group B } \\
\text { (Trichloroacetic acid peel) }\end{array}$ & p-Value* \\
\hline Age (years) & $31.82 \pm 8.23$ & $31.43 \pm 8.22$ & 0.772 \\
\hline Duration (months) & $44.22+20.47$ & $40.96 \pm 22.61$ & 0.360 \\
\hline Baseline MASI score & $17.99 \pm 3.48$ & $18.24 \pm 3.52$ & 0.656 \\
\hline MASI score in 6th week & $10.66 \pm 4.42$ & $12.28 \pm 3.17$ & 0.001 \\
\hline MASI score in 3rd month & $6.62 \pm 3.36$ & $8.23 \pm 4.34$ & 0.012 \\
\hline
\end{tabular}

"Independent sample t-test, MASI: Melasma Area and Severity Index.

In Table 1, a comparison of the quantitative data is made between two treatment groups. At the start of treatment, no significant difference was observed in terms of mean age, duration of symptoms and MASI scores. However, in the $6^{\text {th }}$ week and $3^{\text {rd }}$ month, a significant reduction in mean MASI scores was recorded in group A versus group $B$ with a respective $p$-value of 0.001 and 0.012 revealing greater efficacy of group A combination therapy as shown in Figure 1. Overall, both treatments were found to be effective in 106 (71.6\%) patients.

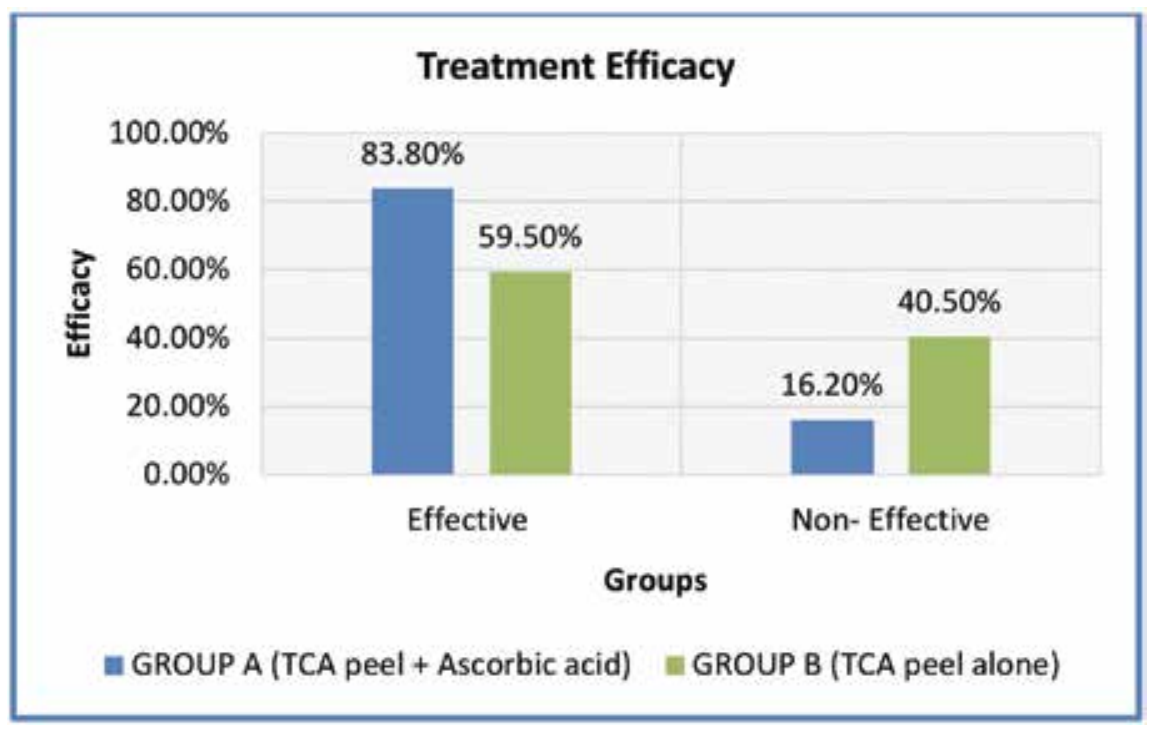

Figure 1: Comparative efficacy of the drugs.

To see the effect modification, data were stratified among different groups as mentioned in Table 2 and Figure 2. The combination therapy used in Group A showed more promising results than Group $B$, particularly in certain categories like age $<30$ years, female gender, Fitzpatrick skin type IV, duration of melasma $<45$ months, $>45$ months and base- line MASI score $>17$ with a respective $p$-value of $0.006,0.004,0.005,0.031,0.011$ and 0.007. However, the results were different in some categories like age $>30$ years and baseline MASI score $<17$ but they did not reach the level of significance ( $p$-value 0.053 and 0.055$)$. 
Table 2: Stratification of drug efficacy among different groups, age, and gender.

\begin{tabular}{|c|c|c|c|c|c|c|c|}
\hline \multirow[b]{2}{*}{ Efficacy } & \multicolumn{3}{|c|}{$\begin{array}{c}\text { Group A } \\
\text { (TCA peel + Ascorbic acid) }\end{array}$} & \multicolumn{3}{|c|}{$\begin{array}{l}\text { Group B } \\
\text { (TCA peel) }\end{array}$} & \multirow[b]{2}{*}{$p$-Value } \\
\hline & Count & $\begin{array}{c}\text { Within- } \\
\text { group } \\
\%\end{array}$ & $\begin{array}{l}\text { Within } \\
\text { efficacy\% }\end{array}$ & Count & $\begin{array}{c}\text { Within- } \\
\text { group } \\
\%\end{array}$ & $\begin{array}{c}\text { Within } \\
\text { Efficacy\% }\end{array}$ & \\
\hline \multicolumn{8}{|c|}{ Comparison of efficacy among groups for age $<30$ years } \\
\hline Effective & 28 & $87.5 \%$ & $58.3 \%$ & 20 & $57.1 \%$ & $41.7 \%$ & \multirow{3}{*}{0.006} \\
\hline Non-effective & 4 & $12.5 \%$ & $21.1 \%$ & 15 & $42.9 \%$ & $78.9 \%$ & \\
\hline Total & 32 & $100 \%$ & $47.8 \%$ & 35 & $100 \%$ & $52.2 \%$ & \\
\hline \multicolumn{8}{|c|}{ Comparison of efficacy among groups for age $>30$ years } \\
\hline Effective & 34 & $81 \%$ & $58.6 \%$ & 24 & $61.5 \%$ & $41.4 \%$ & \multirow{3}{*}{0.053} \\
\hline Non-effective & 8 & $19 \%$ & $34.8 \%$ & 15 & $38.5 \%$ & $65.2 \%$ & \\
\hline Total & 42 & $100 \%$ & $51.9 \%$ & 39 & $100 \%$ & $48.1 \%$ & \\
\hline \multicolumn{8}{|c|}{ Comparison of efficacy among groups for the male gender } \\
\hline Effective & 16 & $88.9 \%$ & $64 \%$ & 9 & $69.2 \%$ & $36 \%$ & \multirow{3}{*}{0.172} \\
\hline Non-effective & 2 & $11.1 \%$ & $33.3 \%$ & 4 & $30.8 \%$ & $66.7 \%$ & \\
\hline Total & 18 & $100 \%$ & $58.1 \%$ & 13 & $100 \%$ & $41.9 \%$ & \\
\hline \multicolumn{8}{|c|}{ Comparison of efficacy among groups for the female gender } \\
\hline Effective & 46 & $82.1 \%$ & $56.8 \%$ & 35 & $57.4 \%$ & $43.2 \%$ & \multirow{3}{*}{0.004} \\
\hline Non-effective & 10 & $17.9 \%$ & $27.8 \%$ & 26 & $42.6 \%$ & $72.2 \%$ & \\
\hline Total & 56 & $100 \%$ & $47.9 \%$ & 61 & $100 \%$ & $52.1 \%$ & \\
\hline
\end{tabular}

${ }^{*}$ Chi-square test, Trichloroacetic Acid (TCA).

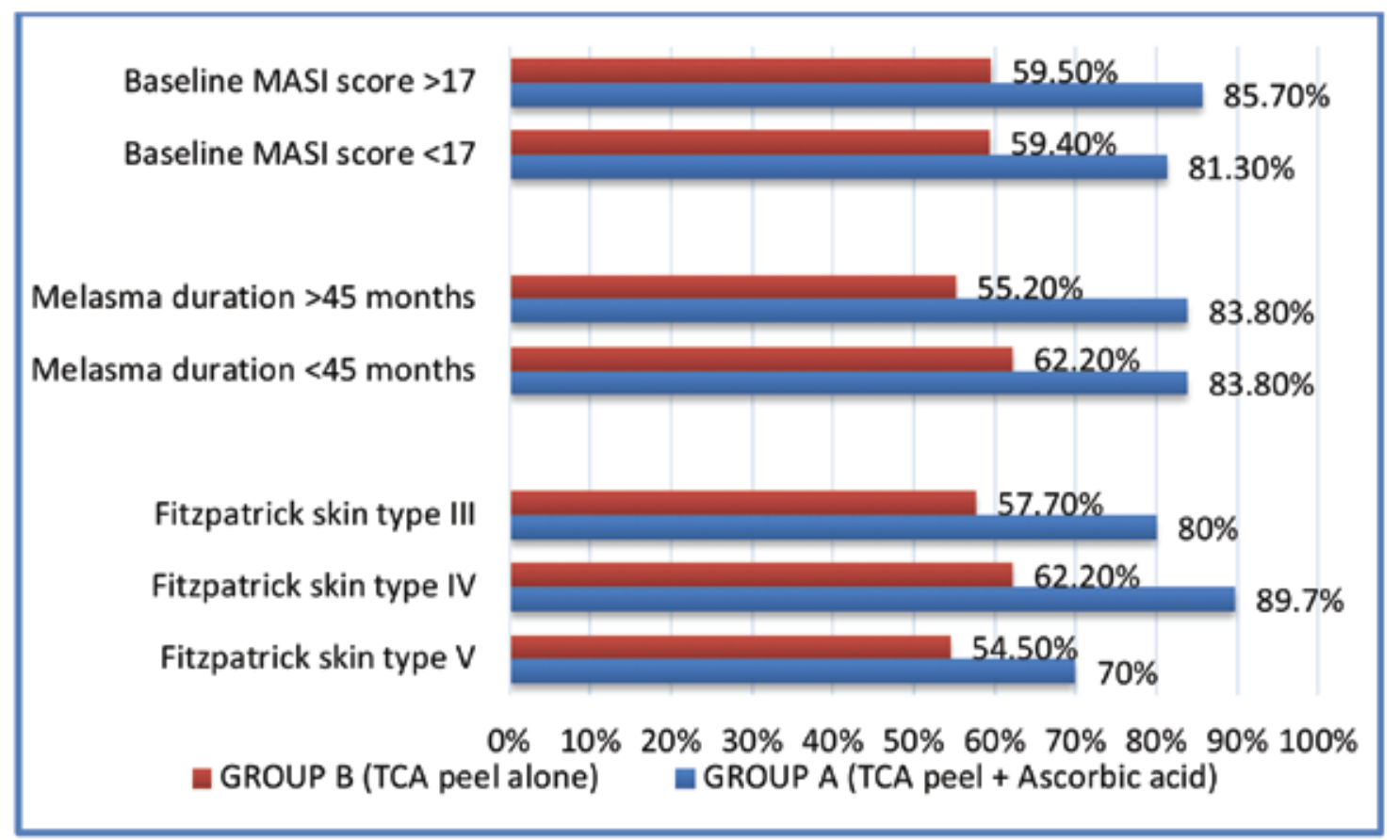

Figure 2: Stratification of drug efficacies among Melasma Area and Severity Index (MASI) scores, melasma duration and skin types.

\section{DISCUSSION}

The combination of trichloroacetic acid peel and ascorbic acid was more effective than trichloroacetic acid peel alone. Melasma is a troublesome condition affecting mostly the younger age groups. It is difficult to manage due to its relapsing nature so physician's main aim is to achieve the tailored goals with a variety of treatment modalities but no single 
remedy is $100 \%$ effective ef, $^{1,3}$. In epidermal melasma, certain melanocytes get hyper-activated upon exposure to UV rays under the influence of genetic background and female hormones ${ }^{17}$. Therefore, inhibition of melanin synthesis is the mainstay of management. Peeling agents in this regard have shown promising results with better efficacy and feasibility of outdoor procedures ${ }^{11}$. Trichloroacetic acid has become the gold standard of chemical peeling agents which remove the unwanted melanin by causing a controlled chemical exfoliation of the skin $^{18}$. In literature, enough evidence is available about its effectiveness as an individual peeling agent but less is known about its use in combination. Topical ascorbic acid is reported to augment the treatment response of peeling agents ${ }^{13,19}$.

Based on the above data, we wanted to evaluate the efficacy of TCA peel alone and in combination with topical ascorbic acid in the local patients of epidermal melasma with skin types II, III and IV by recruiting 74 subjects in each treatment group. Results displayed that combination therapy was more effective than monotherapy $183.8 \%$ versus $59.5 \%)$. A similar study was conducted in 2007 by Soliman et al. but on a very small sample size of only 15 patients in each treatment group without including the Fitzpatrick skin type $\mathrm{V}^{14}$. In our study the mean age of patients was 31.63 years with the age range of 23 to 39 years, resembling the findings of the study by Javaheri et al. with a mean age of 32.30 years ranging from 24 to 45 years ${ }^{20}$.

In some studies, researchers compared TCA monotherapy with other drug combinations e.g., Murtaza et al. compared the efficacy of TCA Peel alone with combined topical magnesium ascorbyl phosphate showing a significant reduction in MASI score in the combination treatment group as compared to TCA peel alone (81.1\% versus $66.2 \%$ ) somewhat like our results. Moreover, there are some other similarities like the predominance of female gender and distribution pattern of Fitzpatrick skin types displaying type IV as the most common type 5 .

Dayal et al ${ }^{21}$ validated the earlier findings of Soliman et al. and Murtaza et al. They compared the MASI scores and Melasma Quality of Life scores in both treatment groups where the respective mean baseline MASI scores in the combination group and control group were 23.55 \pm 4.61 and $23.61 \pm 4.08$ while at the end of the $6^{\text {th }}$ week, scores

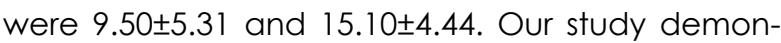
strated the mean MASI scores for the combination group and TCA alone group as $17.99 \pm 3.48$ and $18.24 \pm 3.52$ versus $6.62 \pm 3.36$ and $8.23 \pm 4.34$ at the start and end of treatment, respectively. The baseline scores were less in our study but this could be due to the difference in presentation time of patients. Overall, both studies favor the use of com- bination drug therapy.

We had also stratified the data to see the effect of modifications. The combination therapy was found to be more efficacious than monotherapy for most of the sub-groups like age <30 years, female gender, Fitzpatrick skin type IV, duration of melasma $<45$ months, >45 months and baseline MASI score $>17$, signifying the importance of this drug combination. Surveys showed that conditions that need prolonged treatment or exhibit slow responses to medications always harm self-esteem. The immediate response of chemical peeling improves the quality of life of patients by increasing their self-esteem ${ }^{6,22}$. In patients where the peeling process is unbearable due to severe side-effects or other objective reasons, ascorbic acid alone in the form of topical application can be served as a good alternative with comparable results ${ }^{23}$. It has shown relatively better results than some of its competitors when used as a sole agent in the treatment of melasma ${ }^{14,24}$. It reduces the synthesis of melanin by affecting the activity of tyrosinase ${ }^{25}$. In addition, it also exhibits the antioxidant effect (preventing the production of free radicals that trigger melanogenesis) and the photoprotective effect (preventing the absorption of UV rays) ${ }^{26}$.

There were also some limitations in this study: small sample size, inclusion of patients with epidermal melasma only and lack of data regarding recurrence among the treated patients. Multicenter studies with a large sample size including patients of epidermal, dermal, and mixed melasma, along with a follow-up period of longer duration are required to validate the results.

\section{CONCLUSION}

The combination of trichloroacetic acid peel and topical ascorbic acid was found more effective than trichloroacetic acid peel alone in the treatment of epidermal melasma. We also observed Fitzpatrick type IV (51\%) as the dominant skin type.

\section{ACKNOWLEDGEMENTS}

The authors would like to acknowledge Lt. Col. Dr. Aisha Akhtar for her guidance, technical and clinical support.

\section{CONFLICT OF INTEREST}

The authors declare no conflict of interest.

\section{ETHICS APPROVAL}

Institutional approval for this study was granted by Major General Wasim Alamgir, President of Ethical Committee, Pak-Emirates Military Hospital, Rawalpindi.

\section{PATIENT CONSENT}


Informed verbal consent was taken from the patients after providing necessary information about the study protocol.

\section{AUTHORS' CONTRIBUTION}

SS planned the study and collected clinical data. MSF designed the study and wrote the manuscript. AJ analyzed and interpreted the collected data. MS helped in statistical analysis, bibliography, and critical review of the manuscript.

\section{REFERENCES}

1. Katsambas AD, Lotti TM, Dessinioti C, D'Erme AM, editors. European handbook of dermatological treatments. Springer, p. 1123.doi: 10.1007/978-3-66245139-7

2. Kaliterna D, Kristina Z, Kovacevic I. Melasma-review of current treatment modalities and efficacy assessment of a new resorcinol-based topical formulation. J Clin Cosmet Dermatol. 2017;3:2576-826. doi: 10.16966/2576-2826.116

3. Majeed S, Mahmood N, Ahmed S. Comparative efficacy of topical $4 \%$ hydroquinone vs. $4 \%$ hydroquinone plus $10 \%$ mandelic acid in the treatment of melasma. J Pak Assoc Dermatol. 2018;28(3):31 1-314. 4. Dharni R, Madke B, Singh AL. Correlation of clinicodermatoscopic and Wood's lamp findings in patients having melasma. Pigment Int. 2018;5(2):91-95. doi: 10.4103/Pigmentinternational.Pigmentinternational_

5. Murtaza F, Bangash AR, Khushdil A, Noor SM. Efficacy of trichloro-acetic acid peel alone versus combined topical magnesium ascorbyl phosphate for epidermal melasma. J Coll Physicians Surg Pak. 2016;26(7):557-561.

6. Kouris A, Platsidaki E, Christodoulou C, Efstathiou $\mathrm{V}$, Markantoni V, Armyra K, et al. Patients' self-esteem before and after chemical peeling procedure. J Cosmet Laser Ther. 2018;20(4):220-222. doi: 10.1080/14764172.2017.1400168

7. Al-Talib H, Al-Khateeb A, Hameed A, Murugaiah C. Efficacy and safety of superficial chemical peeling in treatment of active acne vulgaris. An Bras Dermatol. 2017;92(2):212-216. doi: 10.1590/abd1806-4841.201752 73

8. Bagherani N, Smoller BR. Journal highlight: An overview on interesting articles. Glob Dermatol. 2016; 3(6): 394-396. doi: 10.15761/GOD.1000197

9. Sarkar R, Gokhale N, Godse K, Ailawadi P, Arya L, Sarma $N$, et al. Medical management of melasma: A review with consensus recommendations by Indian pigmentary expert group. Indian J Dermatol. 2017;62(6):558-577. doi: 10.4103/ijd.IJD_489_17

10. Ogbechie-Godec OA, Elbuluk N. Melasma: An up-to-date comprehensive review. Dermatol Ther. 2017;7(3):305-318. doi: 10.1007/s13555-017-0194-1 11. Arif T. Salicylic acid as a peeling agent: a comprehensive review. Clin Cosmet Investig Dermatol. 2015; 8: 455-461. doi: 10.2147/CCID.S84765

12. Oyedeji FO, Obaroakpo-Akemu OC. Simultaneous determination of hydroquinone, kojic acid and
L-ascorbic acid in some cosmetic emulsions. Int J Sci. 2017;6(08):46-52. doi: 10.18483/ijSci.1367

13. Pillaiyar T, Manickam M, Namasivayam V. Skin whitening agents: medicinal chemistry perspective of tyrosinase inhibitors. J Enzyme Inhib Med Chem. 2017;32(1):403-425. doi: 10.1080/14756366.2016.1256 882

14. Soliman MM, Ramadan SAR, Bassiouny DA, Abdelmalek M, Marwa. Combined trichloroacetic acid peel and topical ascorbic acid versus trichloroacetic acid peel alone in the treatment of melasma: A comparative study. J Cosmet Dermatol. 2007;6(2):89-94. doi: 10.1111/j.1473-2165.2007.00302.x

15. Majid I, Haq I, Imran S, Keen A, Aziz K, Arif T. Proposing melasma severity index: A new, more practical, office-based scoring system for assessing the severity of melasma. Indian J Dermatol. 2016;61 (1):39-44. doi: 10.4103/0019-5154.174024

16. Pandya AG, Hynan LS, Bhore R, Riley FC, Guevara IL, Grimes P, et al. Reliability assessment and validation of the Melasma Area and Severity Index (MASI) and a new modified MASI scoring method. J Am Acad Dermatol. 2011;64(1):78-83. doi: 10.1016/j.jaad.2009.10.051

17. Passeron T, Picardo M. Melasma, a photoaging disorder. Pigment Cell Melanoma Res. 2018;31 (4):461465. doi: doi.org/10.1111/pcmr.12684

18. Garg S, Thami GP, Bhalla M, Kaur J, Kumar A. Comparative efficacy of a $35 \%$ glycolic acid peel alone or in combination with a $10 \%$ and $20 \%$ trichloroacetic acid spot peel for melasma: A randomized control trial. Dermatol Surg. 2019;45(11):1394-1400. doi: 10.1097/DSS.0000000000001964

19. Rullan PP, Karam AM. Chemical peels for aging faces of all skin types. Rejuvenation of the Aging Face. 2015:79.

20. Javaheri SM, Handa S, Kaur I, Kumar B. Safety and efficacy of glycolic acid facial peel in Indian women with melasma. Int J Dermatol. 2001;40(5):354-357. doi: 10.1046/j.1365-4362.2001.01149.x

21. Dayal S, Sahu P, Yadav M, Jain V. Clinical efficacy and safety on combining $20 \%$ trichloroacetic acid peel with topical $5 \%$ ascorbic acid for melasma. J Clin Diagn Res. 2017;1 1(9): WC08-WC11. doi: 10.7860/JCDR/2017/26078.10685

22. Gupta S, Mahendra A, Jindal A, Kaur G. A study of the clinical profile and assessment of the quality of life in patients of Melasma. J Pharm Innov. 2017;6(7, Part C): 190-193.

23. Aboul-Einien MH, Kandil SM, Abdou EM, Diab HM, Zaki MS. Ascorbic acid derivative-loaded modified aspasomes: formulation, in vitro, ex vivo and clinical evaluation for melasma treatment. J Liposome Res. 2020;30(1):54-67. doi: 10.1080/08982104.2019.1585448 24. Guevara IL, Pandya AG. Safety and efficacy of $4 \%$ hydroquinone combined with $10 \%$ glycolic acid, antioxidants, and sunscreen in the treatment of melasma. Int J Dermatol. 2003;42(12):966-972. doi: 10.1111/j.1365-4632.2003.02017.x

25. Lee SA, Son YO, Kook SH, Choi KC, Lee JC. Ascor- 
bic acid increases the activity and synthesis of tyrosinase in Bl6F10 cells through activation of p38 mitogen-activated protein kinase. Archives of dermatological research. 2011;303(9):669-678. doi: 10.1007/s00403-011-1158-4

26. Nahhas AF, Abdel-Malek ZA, Kohli I, Braunberger
$\mathrm{TL}$, Lim HW, Hamzavi IH. The potential role of antioxidants in mitigating skin hyperpigmentation resulting from ultraviolet and visible light-induced oxidative stress. Photodermatol Photoimmunol Photomed. 2019;35(6):420-428. doi: 10.1111/phpp.12423. 